\title{
Predictors of Peri-Ophthalmic Aneurysm Incomplete Occlusion and Visual Symptoms After Treatment with a Pipeline Embolization Device: A Multi-Center Cohort Study
}

\section{CHAO XU}

Harbin Medical University https://orcid.org/0000-0002-7179-697X

\section{PEI WU}

Harbin Medical University

\section{BOWEN SUN}

Harbin Medical University

\section{SHANCAI XU}

Harbin Medical University

\section{BIN LUO}

Capital Medical University, Beijing

\section{XINJIAN YANG}

Capital Medical University, Beijing

HUAIZHANG SHI ( $\nabla$ shihuaizhang@hrbmu.edu.cn )

Harbin Medical University https://orcid.org/0000-0003-3150-6234

\section{Research Article}

Keywords: pipeline embolization device, coil, ophthalmic artery, aneurysm, visual outcome

Posted Date: September 8th, 2021

DOI: https://doi.org/10.21203/rs.3.rs-844536/v1

License: (a) (i) This work is licensed under a Creative Commons Attribution 4.0 International License. Read Full License 


\section{Abstract}

Objective: Peri-ophthalmic aneurysm is a special type of aneurysm. We assessed the relationship between ophthalmic artery (OA) origin and aneurysm and examined the effect of a pipeline embolization device (PED, Covidien/Medtronic) with or without coils on aneurysm occlusion rate and visual outcomes.

Methods: We retrospectively analyzed 194 peri-ophthalmic aneurysms in 189 patients among 1,171 patients treated with a PED in a Chinese post-market multi-center registry study from November 2014 to October 2019. Peri-ophthalmic aneurysms were defined as carotid-ophthalmic segment aneurysms arising from the internal carotid artery dorsal wall at, or distal to, the OA origin, with a superior or superomedial projection. The relationship between $O A$ origin and the aneurysm was classified as follows: Type A, OA originating separate from the aneurysm; Type B, OA originating from the aneurysm neck or dome. Patients with aneurysm were divided into the PED-only group and the PED + coils group according to treatment.

Results: The median follow-up time was 6.8 months (range, 5.3-20.2 months). There were 163 occluded aneurysms (84\%) and 31 aneurysms with incomplete occlusion (16\%). A multivariate analysis showed that Type $B$ aneurysm was a risk factor for incomplete occlusion in the PED-only group (odds ratio [OR] $4.951,95 \%$ confidence interval $[\mathrm{Cl}] 1.904-12.875, \mathrm{p}=0.001)$. Visual symptoms at final follow up correlated with preoperative visual symptoms (OR 16.005, 95\% Cl 2.505-102.273, $p=0.003$ ).

Conclusions: Type B aneurysm is associated with a lower occlusion rate after PED-only treatment. Patients with preoperative visual symptoms should be treated promptly to avoid permanent visual symptoms.

\section{Introduction}

Peri-ophthalmic aneurysms account for $5 \%-10 \%$ of intracranial aneurysms. Peri-ophthalmic aneurysms often involve ophthalmic arteries and may occur in combination with tandem aneurysms. The complication rate of peri-ophthalmic aneurysms remains high, regardless of clipping or stent-assisted embolization treatment $[7,9,15,21,22]$. However, a large number of researchers have reported the effectiveness and safety of pipeline embolization devices (PEDs) for the treatment of carotid-ophthalmic aneurysms $[7,9,15,21,22]$. Despite this, there are some issues that are rarely considered. On the one hand, little consideration has been given to the prognostic impact of the anatomical relationship between the ophthalmic artery and the aneurysm, on the other hand, different treatment methods, such as PEDonly or PED + coils, have not been thoroughly investigated for their effect on aneurysm occlusion rate and visual symptoms. In this study, we retrospectively analyzed peri-ophthalmic aneurysms treated with a PED in the China post-market multi-center registry study (PLUS) to explore risk factors for aneurysm occlusion and visual symptoms.

\section{Methods}




\section{Design and Process}

We performed a retrospective review using a database of 14 participating Chinese institutions for aneurysms treated with PEDs between November 2014 and October 2019 in the PLUS. The study was a consecutive, real-world cohort registry study. Local institutional review boards or ethics committees approved the study and use of patients' data. All operations were performed with written informed consent from patients.

The inclusion criterion was peri-ophthalmic aneurysm identified as aneurysm of the carotid-ophthalmic segment arising from the dorsal wall of the internal carotid artery (ICA) at, or just distal to, the origin of the ophthalmic artery, with a superior or superomedial projection[15]. Aneurysms were not included if they arose from the ventral or lateral wall of the ICA, the carotid cave, or the cavernous segment.

Recurrent, blister, pseudo, dissecting, and fusiform aneurysms were excluded. The relationship between ophthalmic artery origin and aneurysm was categorized according to the classification of Griessenauer et al[10]. Since Type 3 was only observed in two cases, we classified Type 1 as Type A and Type 2 and Type 3 as Type B. Because $36 \%$ of patients in this study used adjuvant coils, we divided patients into the PEDonly group and the PED + coils group.

Data on patient demographics, clinical characteristics, aneurysm features (side, aneurysm classification, whether or not a combination of tandem aneurysms existed, parent artery diameter, maximum aneurysm diameter, aneurysm neck), treatment characteristics (PED size and PED number, intraoperative and postoperative complications), and follow-up characteristics (follow-up duration, aneurysm occlusion rate, ophthalmic artery fate, modified Rankin Scale [mRS] score, and visual symptoms) were collected.

Follow-up digital subtraction angiography (DSA) was performed 6 months after operation and repeated again between 12 and 36 months. Aneurysm occlusion was classified using the O'Kelly-Marotta (OKM) grading scale[16]. We described ophthalmic artery alterations covered by the PED as follows: 1) no change, 2) diminished flow, 3) occlusion.

Visual symptoms, such as loss of visual field, decreased visual acuity, blurred vision, and amaurosis fugax, were investigated. For patients with preoperative visual symptoms, visual acuity and visual field were examined by an ophthalmologist preoperatively and postoperatively. Visual acuity and visual field tests were also performed for patients who developed new visual symptoms postoperatively. Patients were grouped according to presence or absence of visual symptoms at final follow up.

\section{Perioperative Management}

All patients received an antiplatelet regimen that included aspirin (100 or $300 \mathrm{mg} /$ day) and clopidogrel (75 mg/day for 5 days) prior to surgery. Patients who were identified as clopidogrel non-responders received aspirin (100 mg/day) and ticagrelor (90 mg twice/day). All patients demonstrated suppression of optimal platelet activity before PED placement. Board-certified neuro-endovascular surgeons performed all procedures. Intravenous heparin was administered intraoperatively to achieve an activated 
clotting time of $>250$ seconds. Heparin was discontinued after completing the procedure. Patients were administered continuous dual antiplatelet therapy after PED placement, including aspirin (100 mg/day), clopidogrel ( $75 \mathrm{mg} /$ day), or ticagrelor ( $90 \mathrm{mg} /$ day) for 6 months. After 6 months, the decision to discontinue clopidogrel or ticagrelor was made according to the results of angiography. Aspirin (100 $\mathrm{mg} /$ day) was recommended for life.

\section{Statistical Analysis}

Categorical variables are reported as proportions, and continuous variables are reported as mean \pm standard deviation or median and interquartile range, as appropriate. Between groups, variables were compared using the Chi-squared test, the Mann-Whitney $U$ test, or the t-test. Factors related to incomplete aneurysm occlusion were analyzed in the PED-only group and the PED + coils group. A univariate analysis was used to test the following independent factors: age, sex, hypertension, diabetes, smoking, aneurysm features, treatment characteristics, and follow up duration. Factors that were predictive in the univariate analysis $(P<0.20)$ were entered into a multivariate regression analysis. $P$ values of $<0.05$ were considered statistically significant. Univariate and multivariate analysis the relevant factors of visual symptoms of last follow-up. All statistical analyses were performed using SPSS 25 (IBM Corp., Armonk, NY, USA).

\section{Results}

\section{Patient and Aneurysm Characteristics}

Patient characteristics are summarized in Table 1. A total of 194 peri-ophthalmic aneurysms in 189 patients were retrospectively identified, 151 patients $(79.9 \%)$ were female and 38 patients $(20.1 \%)$ were male. The mean age of patients was $53 \pm 9.4$ years (range, $19-78$ years). Five patients with 10 aneurysms were diagnosed with bilateral peri-ophthalmic aneurysm. Type $A$ aneurysms were present in 130 patients (68.8\%), while Type B aneurysms were present in 59 patients (31.2\%). There were 55 patients with tandem aneurysms involving other locations. Of all 194 aneurysms, 79 (40.7\%) exhibited headache as the clinical manifestation, $1(0.5 \%)$ demonstrated subarachnoid hemorrhage for 40 days, 26 $(13.4 \%)$ had a chief complaint of visual symptoms, and 88 (45.3\%) were incidentally and asymptomatically diagnosed. Smoking, hypertension, and diabetes mellitus were reported in 37 (19.6\%), 48 (25.4\%), and 11 (5.8\%) patients, respectively. Parent artery diameter, maximum aneurysm diameter, and aneurysm neck width were $3.96 \pm 0.63 \mathrm{~mm}, 7.49 \pm 5.83 \mathrm{~mm}$, and $5.27 \pm 2.67 \mathrm{~mm}$, respectively. Of 189 patients, 183 were treated with 1 PED, 5 were treated with 1 PED bilaterally, and 1 was treated with 2 PEDs. The mean PED size was $4.18 \pm 0.46 \mathrm{~mm}$. Among patients, 121 had 122 aneurysms treated with a PED-only, while 68 had 72 aneurysms treated with a PED + coils. In these two groups, hypertension was reported in $25(20.7 \%)$ and $23(17.3 \%)$ patients, respectively. Ten patients (8.2\%) presented with visual symptoms in the PED-only group, while 16 patients (22.2\%) presented with visual symptoms in the PED + coils group. The maximum aneurysm diameter was $5.90 \pm 3.81 \mathrm{~mm}$ and $10.18 \pm 7.46 \mathrm{~mm}$, respectively, in 
the PED-only and PED + coils groups. The aneurysm neck width was $4.58 \pm 2.11 \mathrm{~mm}$ and $6.45 \pm 3.07$ $\mathrm{mm}$, respectively, in the PED-only and PED + coils groups (Table 1).

\section{Clinical and Imaging Findings}

Preoperative mRS scores of 0-2 were available for 188 patients, 1 patient had an mRS score of 4, and a final postoperative follow-up mRS score of 0-2 was available for 189 patients. Complications occurred in 14 patients $(7.2 \%)$, including intraoperative cerebral hemorrhage in 2 patients (1\%), postoperative ischemia in 12 patients (6.2\%), and ischemia at final follow up in 4 patients (2.1\%). Postoperative ischemia occurred in 11 patients (15.3\%) in the PED + coils group and in 1 patient (0.8\%) in the PED-only group. A statistically significant difference was observed between the two groups. No significant difference in ischemia at final follow up was observed between the two groups, with 2 cases (1.6\%) in the PED + coils group and 2 cases (2.8\%) in the PED-only group.

\section{Visual Outcomes}

Of 194 aneurysms, 26 aneurysms (13.4\%) were associated with visual symptoms as the chief complaint. At final follow up, visual symptoms occurred in 9 aneurysms (4.6\%), 6 (66.7\%) of which also had preoperative visual symptoms. Visual symptoms improved after operation in 20 aneurysms (76.9\%), including 14 in the PED + coils group and 6 in the PED-only group. However, visual symptoms at final follow up were not significantly different between the two groups $(P=0.729)$. Three cases of new visual symptoms after operation accounted for $1.7 \%$ of the non-visual symptoms group. Visual symptoms at final follow up was not significantly different between the Type $A$ and Type $B(P=0.391)$, either in the PEDonly group $(P=0.187)$ or the PED + coils group $(P=0.851)$, (Table 2, Table 5).

\section{Aneurysm Occlusion at Final Follow up}

Angiography at final follow up (median, 6.8 months, range, 5.3-20.2) demonstrated OKM D type occlusion in 163 aneurysms (84\%) (Table 2), including 96 aneurysms (78.7\%) in the PED-only group (72 Type A [Fig. 1] and 24 Type B) and 67 aneurysms (93.1\%) in the PED + coils group (49 Type A and 18 Type B) (Table 2, Table 5). Of the 61 Type B aneurysms, the aneurysm occlusion rate was $60 \%$ in the PEDonly group (24/40)) and 85.7\% in the PED + coils group (18/21) (Table 5). OKM A-, B-, and C-type occlusion were observed in 31 aneurysms (16\%), including 26 in the PED-only group (10 Type A and 16 Type B [Fig. 2]) and 5 in the PED + coils group (2 Type A and 3 Type B [Fig. 3]). The ophthalmic artery was occluded at final follow up in 1 case (0.5\%), diminished flow was observed in 12 cases (6.2\%), and no flow change was observed in 181 cases (93.3\%) (Table 2$)$.

\section{Outcome of the Multivariate Analysis}

Only Type B aneurysm was associated with incomplete aneurysm occlusion with a multivariate analysis in the PED-only group (odds ratio [OR] 4.951, 95\% confidence interval [CI] 1.904-12.875, p = 0.001, Table 3). No factors associated with incomplete aneurysm occlusion were identified in the PED + coils group 
(Table 3). Preoperative visual symptom complaints (OR 16.005, 95\% Cl 2.505-102.273, $\mathrm{p}=0.003$ ) in the multivariate analysis were predictors of visual symptoms at final follow up (Table 4).

\section{Discussion}

In the treatment of peri-ophthalmic aneurysms with PEDs, physicians are most concerned about factors related to aneurysm occlusion and changes in vision. However, the effect of the anatomical relationship between the ophthalmic artery and aneurysm on treatment is poorly studied. We reviewed peri-ophthalmic aneurysms treated in the PLUS study and explored factors that promote aneurysm occlusion and reduce visual symptoms.

Preoperative visual symptoms, preoperative mRS score, maximum aneurysm diameter, and aneurysm neck width in the PED + coils group in this study were more frequent/higher compared with the PED-only group, probably due to significant clinical symptoms produced by the large aneurysm diameter by compression of peripheral vessels, optic nerves, ophthalmic nerves, and trochlear nerves[22]. Previous studies suggest that PED + coils should be used for large wide-necked aneurysms, either to reduce jet flow, increase aneurysm wall protection and reduce the risk of aneurysm re-rupture, or act as a scaffold to fix the PED and prevent long-term PED migration and shortening[14]. Differences in morphology between the two groups may lead to greater selection bias in treatment. In this study, PED + coils treatment was used in $37.1 \%$ of patients. To avoid this effect, we analyzed the two treatment methods separately. Lin et al.[14] compared PED-only treatment with PED + coils treatment for intracranial aneurysms with a mean follow up of 7.8 months. They reported $74.7 \%$ occlusion in the PED-only group and $93.1 \%$ in the PED + coils group. Although only peri-ophthalmic aneurysms were included in our study, with a median followup time of 6.8 months, the occlusion rate was $78.7 \%$ in the PED-only group and $93.1 \%$ in the PED + coils group. A meta-analysis by Touzé et al.[25] examined 913 cases of ophthalmic segment aneurysm. In this meta-analysis, most studies used a PED only with an average follow-up duration of 16.4 months, and the aneurysm occlusion rate reached $85 \%$. In our study, the median follow-up time was 6.8 months, and the total occlusion rate of peri-ophthalmic aneurysms reached $84 \%$. This shows that PED + coils treatment significantly increases aneurysm occlusion rate.

In the present study, the relationship between ophthalmic artery origin and aneurysm was categorized according to the classification of Griessenauer et al.[10]. Since Type 3 only occurred in two cases, we classified Type 1 as Type A and Type 2 and Type 3 as Type B. In a retrospective study by Griessenauer et al.[9] 66 cases of para-ophthalmic aneurysm were followed up for 6 months and 18 months, and the aneurysm occlusion rates were $70.9 \%$ and $85.5 \%$, respectively. Among 11 cases of incomplete aneurysm occlusion, ophthalmic arteries originated from the aneurysm body in two cases. It is believed that the ophthalmic artery originating from the aneurysm is an influencing factor for incomplete occlusion. In the PED-only group, the occlusion rate of Type A aneurysms was $87.8 \%$, while the occlusion rate of Type B aneurysms was only $60 \%$. Univariate and multivariate analyses in the PED-only group showed that Type $B$ aneurysm with the ophthalmic artery originating from the neck of the aneurysm was an independent risk factor for incomplete aneurysm occlusion. This result is consistent with the conclusion of 
Griessenauer et al.[10] on the importance of the anatomical relationship between the ophthalmic artery and the aneurysm. For aneurysms where the ophthalmic artery originates from the aneurysm body or aneurysm neck, after PED implantation, if the ophthalmic artery still has a sufficient pressure gradient to maintain forward blood flow, sufficient blood flow will be retained in the aneurysm to prevent thrombosis, resulting in an aneurysm that is difficult to occlude[12,15]. This is similar to why aneurysms are difficult to occlude when a PED is used to treat fetal posterior communicating aneurysm[11, 26]. In our study, the occlusion rate of Type A aneurysm in the PED + coils group was $96.1 \%$, and the occlusion rate of Type $B$ aneurysm was $85.7 \%$, compared with the $60 \%$ occlusion rate of Type B aneurysm in the PED-only group, indicating that application of coils increases the occlusion rate of Type B aneurysms. Univariate and multivariate analyses in the PED + coils group did not identify other factors that promote aneurysm occlusion. The long-term effects of coils on the ophthalmic artery and visual symptoms are worth exploring.

Previous reports have shown that with PED treatment of ophthalmic artery segment aneurysms, the preservation rate of the ophthalmic artery is between $68 \%$ and $97 \%[1,3,4,7-9,15,17-19,27]$. Moreover, a recent meta-analysis by Touzé et al. suggested an ophthalmic artery preservation rate of $90 \%[25]$. The overall ophthalmic artery preservation rate in this group was $93.3 \%, 94.3 \%$ in the PED-only group, and $91.7 \%$ in the PED + coils group. Although ophthalmic arteries with diminished flow and occlusion occurred more frequently in the PED + coils group compared with the PED-only group, there were no significant differences between the two groups.

Previous studies have shown that $16 \%-40 \%$ of patients with para-ophthalmic aneurysms have visual symptoms [5, 13, 20-22]. Among the 194 aneurysms in this group, 26 (13.4\%) were associated with visual symptoms as the chief complaint, and 20 (76.9\%) were associated with improved visual symptoms postoperatively. In a meta-analysis of ophthalmic segment aneurysms that presented with visual symptoms preoperatively, Sliva et al.[21] reported improvements of $58 \%$ and $49 \%$ after clipping and embolization, respectively, compared with an improvement of $71 \%$ after flow diverter device (FDD) placement. In Sliva's recent study, 15 patients with preoperative visual symptoms had an improvement of 93\% after PED implantation[22]. The postoperative visual symptom improvement rate in this group was $76.9 \%$, which is between the range presented Sliva et al.[21, 22] indicating that for patients with preoperative visual symptoms, FDD treatment has obvious advantages compared with other treatment methods. Because visual symptoms are most often caused by the aneurysmal mass effect, clipping may aggravate these symptoms due to optic nerve separation. Traditional embolization with dense coils cannot reduce the compression effect of aneurysms. After FDD implantation, as a thrombus forms within the aneurysm sac, the aneurysm gradually shrinks and compression on surrounding structures is relieved[21, 22, 28].

In our study, three cases of new visual symptoms after surgery accounted for $1.7 \%$ of the non-visual symptoms group. In the study of FDD treatment for para-ophthalmic aneurysms that focused on visual symptoms, the proportion of patients with new visual symptoms was less than $5 \%$, but this proportion was higher in studies using specialized ophthalmic examinations $[6,7,10,17,23,24]$. At present, no study 
has illustrated that changes in the ophthalmic artery are associated with new visual symptoms in patients. Touzé et al.[24] believed that the ophthalmic artery has abundant external carotid anastomotic branch compensation, and when the origin of the ophthalmic artery is covered by FDD, the ophthalmic artery and the external carotid anastomotic branch need to achieve a new pressure balance. During establishment of this process, if retinal perfusion pressure is reduced, symptoms of amaurosis fugax may be apparent. For Type B aneurysms, dislodged microthrombi also cause emboli in retinal branch arteries after intra-aneurysmal thrombosis, resulting in visual field defects[19, 24].

In this study, although the visual symptom rate at final follow up was $5.6 \%$ in the PED + coils group and $4.1 \%$ in the PED-only group, there was no significant difference between the two groups. The multivariate analysis showed that the visual symptoms at final follow up had no correlation with changes in the ophthalmic artery, aneurysm type, or treatment method. This is consistent with the conclusion that visual symptoms at final follow up were not related to changes in the ophthalmic artery in a previous study[25]. In our study, $66.7 \%$ of patients with visual symptoms at final follow up had preoperative visual symptoms. First, it takes time to recover from the visual symptoms caused by the aneurysmal mass effect. Second, previous studies have suggested that 1 month of onset may be the optimal time for recovery of visual symptoms, since long-term compression may cause difficulty in recovery[2, 28], but the patients in our study all had visual symptoms for more than 2 months. In addition, we did not conduct objective and systematic eye examinations during follow up, thus, there may be certain deviations that affect the final multi-factor analysis results.

\section{Limitations}

There are some limitations to this study that should be noted. First, the study was a retrospective, multicenter study, and heterogeneity in operators' surgical preferences cannot be well quantified. Second, patients did not undergo an objective and systematic eye examination during follow up, which may have influenced the final results. We believe a prospective study with a systematic design is required to evaluate the current treatment of para-ophthalmic artery aneurysms with FDDs.

\section{Conclusions}

From our results, we conclude that PED-only treatment has a low occlusion rate for Type B aneurysm. Appropriate application of coils could increase the occlusion rate of aneurysms and the incidence of ophthalmic artery occlusion and visual symptoms is low. PED + coils treatment is safe for patients with Type B aneurysms. However, for patients with preoperative visual symptoms, some patients may not achieve relief of symptoms postoperatively. Such patients should be treated in a timely manner to avoid permanent visual symptoms.

\section{Declarations}


Funding: This study was funded by National Nature Science Foundation of China (Grant no. 82071309), National Natural Science Foundation of China (Grant no. 81901190), Natural Science Foundation of Heilongjiang Province of China (Grant no. YQ2019H015).

Conflicts of interest/Competing interests: The authors report no conflict of interest concerning the materials or methods used in this study or the findings specified in this paper.

Availability of data and material: All the data of this study can be obtained in the article and supplementary materials.

Code availability $₫$ Not applicable.

Ethics approval: This trial was approved by the Institutional Review Board (IRB) of Beijing Tiantan Hospital Affiliated to Capital Medical University. Ethical review No: KY 2018-098-02.

Consent to participate: This trial was registered with ClinicalTrials.gov identifier: NCT03831672 and waiver of one or more elements of informed consent.

Consent for publication: The authors declare that there is no conflict of interest regarding the publication of this paper.

Author contributions: Conception and design: $\mathrm{Xu}, \mathrm{Wu}$. Acquisition of data: $\mathrm{Xu}, \mathrm{Wu}, \mathrm{Luo}$. Analysis and interpretation of data: Xu, Sun, Luo. Drafting the article: Xu. Critically revising the article: all authors. Reviewed submitted version of manuscript: all authors. Approved the final version of the manuscript on behalf of all authors: HZ Shi. Statistical analysis: Xu, Shancai Xu. Study supervision: HZ Shi, XJ Yang.

\section{References}

1. Bhogal P, Ganslandt O, Bäzner H, Henkes H, Pérez MA. The Fate of Side Branches Covered by Flow Diverters-Results from 140 Patients. World neurosurgery. 2017,103:789-98. https://doi.org/10.1016/j.wneu.2017.04.092

2. Brown BL, Lopes D, Miller DA, Tawk RG, Brasiliense LB, Ringer A, et al. The fate of cranial neuropathy after flow diversion for carotid aneurysms. Journal of neurosurgery. 2016,124(4):1107-13. https://doi.org/10.3171/2015.4.jns142790

3. Burrows AM, Brinjikji W. Flow Diversion for Ophthalmic Artery Aneurysms. 2016,37(10):1866-9. https://doi.org/10.3174/ajnr.A4835

4. Chalouhi N, Daou B, Kung D, Zanaty M, Phillips JL, Tjoumakaris S, et al. Fate of the Ophthalmic Artery After Treatment With the Pipeline Embolization Device. Neurosurgery. 2015,77(4):581-4, discussion 4. https://doi.org/10.1227/neu.0000000000000887

5. Day AL. Aneurysms of the ophthalmic segment. A clinical and anatomical analysis. Journal of neurosurgery. 1990,72(5):677-91. https://doi.org/10.3171/jns.1990.72.5.0677 
6. Di Maria F, Pistocchi S, Clarençon F. Flow Diversion versus Standard Endovascular Techniques for the Treatment of Unruptured Carotid-Ophthalmic Aneurysms. 2015,36(12):2325-30. https://doi.org/10.3174/ajnr.A4437

7. Durst CR, Starke RM, Clopton D, Hixson HR, Schmitt PJ, Gingras JM, et al. Endovascular treatment of ophthalmic artery aneurysms: ophthalmic artery patency following flow diversion versus coil embolization. Journal of neurointerventional surgery. 2016,8(9):919-22. https://doi.org/10.1136/neurintsurg-2015-011887

8. Gascou G, Lobotesis K, Brunel H, Machi P, Riquelme C, Eker O, et al. Extra-aneurysmal flow modification following pipeline embolization device implantation: focus on regional branches, perforators, and the parent vessel. AJNR American journal of neuroradiology. 2015,36(4):725-31. https://doi.org/10.3174/ajnr.A4191

9. Griessenauer CJ, Piske RL, Baccin CE, Pereira BJA, Reddy AS, Thomas AJ, et al. Flow Diverters for Treatment of 160 Ophthalmic Segment Aneurysms: Evaluation of Safety and Efficacy in a Multicenter Cohort. Neurosurgery. 2017,80(5):726-32. https://doi.org/10.1093/neuros/nyw110

10. Griessenauer CJ, Ogilvy CS, Foreman PM, Chua MH, Harrigan MR, Stapleton CJ, et al. Pipeline Embolization Device for small paraophthalmic artery aneurysms with an emphasis on the anatomical relationship of ophthalmic artery origin and aneurysm. Journal of neurosurgery. 2016,125(6):1352-9. https://doi.org/10.3171/2015.12.jns152499

11. Kan P, Duckworth E, Puri A, Velat G, Wakhloo A. Treatment failure of fetal posterior communicating artery aneurysms with the pipeline embolization device. Journal of neurointerventional surgery. 2016,8(9):945-8. https://doi.org/10.1136/neurintsurg-2015-011959

12. Kan P, Srinivasan VM, Mbabuike N, Tawk RG, Ban VS, Welch BG, et al. Aneurysms with persistent patency after treatment with the Pipeline Embolization Device. Journal of neurosurgery. 2017,126(6):1894-8. https://doi.org/10.3171/2016.6.jns16402

13. Lai LT, Morgan MK. Outcomes for unruptured ophthalmic segment aneurysm surgery. Journal of clinical neuroscience : official journal of the Neurosurgical Society of Australasia. 2013,20(8):112733. https://doi.org/10.1016/j.jocn.2012.12.004

14. Lin N, Brouillard AM, Krishna C, Mokin M, Natarajan SK, Sonig A, et al. Use of coils in conjunction with the pipeline embolization device for treatment of intracranial aneurysms. Neurosurgery. 2015,76(2):142-9. https://doi.org/10.1227/neu.0000000000000579

15. Moon K, Albuquerque FC, Ducruet AF, Webster Crowley R, McDougall CG. Treatment of ophthalmic segment carotid aneurysms using the pipeline embolization device: clinical and angiographic followup. Neurological research. 2014,36(4):344-50. https://doi.org/10.1179/1743132814y.0000000322

16. O'Kelly C J, Krings T, Fiorella D, Marotta TR. A novel grading scale for the angiographic assessment of intracranial aneurysms treated using flow diverting stents. Interventional neuroradiology : journal of peritherapeutic neuroradiology, surgical procedures and related neurosciences. 2010,16(2):133-7. https://doi.org/10.1177/159101991001600204 
17. Puffer RC, Kallmes DF, Cloft HJ, Lanzino G. Patency of the ophthalmic artery after flow diversion treatment of paraclinoid aneurysms. Journal of neurosurgery. 2012,116(4):892-6. https://doi.org/10.3171/2011.11.jns111612

18. Rangel-Castilla L, Munich SA, Jaleel N, Cress MC, Krishna C, Sonig A, et al. Patency of anterior circulation branch vessels after Pipeline embolization: longer-term results from 82 aneurysm cases. Journal of neurosurgery. 2017,126(4):1064-9. https://doi.org/10.3171/2016.4.jns16147

19. Rouchaud A, Leclerc O, Benayoun Y, Saleme S, Camilleri Y, D'Argento F, et al. Visual outcomes with flow-diverter stents covering the ophthalmic artery for treatment of internal carotid artery aneurysms. AJNR American journal of neuroradiology. 2015,36(2):330-6. https://doi.org/10.3174/ajnr.A4129

20. Sahlein DH, Fouladvand M, Becske T, Saatci I, McDougall CG, Szikora I, et al. Neuroophthalmological outcomes associated with use of the Pipeline Embolization Device: analysis of the PUFS trial results. Journal of neurosurgery. 2015,123(4):897-905. https://doi.org/10.3171/2014.12.jns141777

21. Silva MA, See AP, Dasenbrock HH, Patel NJ, Aziz-Sultan MA. Vision outcomes in patients with paraclinoid aneurysms treated with clipping, coiling, or flow diversion: a systematic review and metaanalysis. Neurosurgical focus. 2017,42(6):E15. https://doi.org/10.3171/2017.3.focus1718

22. Silva MA, See AP, Khandelwal P, Mahapatra A, Frerichs KU, Du R, et al. Comparison of flow diversion with clipping and coiling for the treatment of paraclinoid aneurysms in 115 patients. Journal of neurosurgery. 2018:1-8. https://doi.org/10.3171/2018.1.jns171774

23. Szikora I, Berentei Z, Kulcsar Z, Marosfoi M, Vajda ZS, Lee W, et al. Treatment of intracranial aneurysms by functional reconstruction of the parent artery: the Budapest experience with the pipeline embolization device. AJNR American journal of neuroradiology. 2010,31(6):1139-47. https://doi.org/10.3174/ajnr.A2023

24. Touzé R, Touitou V, Shotar E, Gabrieli J, Drir M, Mathon B, et al. Long-term visual outcome in patients treated by flow diversion for carotid-ophthalmic aneurysms. Journal of neurointerventional surgery. 2018,10(11):1067-73. https://doi.org/10.1136/neurintsurg-2017-013684

25. Touzé R, Gravellier B, Rolla-Bigliani C, Touitou V, Shotar E, Lenck S, et al. Occlusion Rate and Visual Complications With Flow-Diverter Stent Placed Across the Ophthalmic Artery's Origin for CarotidOphthalmic Aneurysms: A Meta-Analysis. Neurosurgery. 2020,86(4):455-63. https://doi.org/10.1093/neuros/nyz202

26. Tsang AC, Fung AM, Tsang FC, Leung GK, Lee R, Lui WM. Failure of Flow Diverter Treatment of Intracranial Aneurysms Related to the Fetal-type Posterior Communicating Artery. Neurointervention. 2015,10(2):60-6. https://doi.org/10.5469/neuroint.2015.10.2.60

27. Vedantam A, Rao VY, Shaltoni HM, Mawad ME. Incidence and clinical implications of carotid branch occlusion following treatment of internal carotid artery aneurysms with the pipeline embolization device. Neurosurgery. 2015,76(2):173-8, discussion 8. https://doi.org/10.1227/neu.0000000000000595

28. Wang Z, Tian Z, Li W, Wang J, Zhu W, Zhang M, et al. Variation of Mass Effect After Using a Flow Diverter With Adjunctive Coil Embolization for Symptomatic Unruptured Large and Giant Intracranial 
Aneurysms. Frontiers in neurology. 2019,10:1191. https://doi.org/10.3389/fneur.2019.01191

\section{Tables}

TABLE 1. Baseline characteristics of 189 patients with 194 peri-ophthalmic aneurysms 


\begin{tabular}{|c|c|c|c|c|}
\hline Characteristic & Total & PED-only & PED + coils & $\mathrm{p}$ Value \\
\hline No. of patients & 189 & $121(64 \%)$ & $68(36 \%)$ & \\
\hline No. of aneurysms & 194 & $122(62.8 \%)$ & $72(37.2 \%)$ & \\
\hline \multirow[t]{2}{*}{ Mean age in yrs (range) } & $53 \pm 9.4$ & $52 \pm 9.1$ & $53 \pm 9.9$ & 0.462 \\
\hline & $(19-78)$ & $(19-73)$ & $(26-78)$ & \\
\hline Sex & & & & 0.165 \\
\hline Female & 151 (79.9\%) & $93(76.9 \%)$ & $58(85.3 \%)$ & \\
\hline Male & $38(20.1 \%)$ & $28(23.1 \%)$ & $10(14.7 \%)$ & \\
\hline Hypertension & $48(25.4 \%)$ & $25(20.7 \%)$ & $23(17.3 \%)$ & $0.046^{*}$ \\
\hline Diabetes & $11(5.8 \%)$ & $5(4.1 \%)$ & $6(8.8 \%)$ & 0.207 \\
\hline Smoking & $37(19.6 \%)$ & $26(21.5 \%)$ & $11(16.2 \%)$ & 0.377 \\
\hline \multicolumn{5}{|l|}{ Presenting symptoms } \\
\hline Headache & $79(40.7 \%)$ & $51(41.8 \%)$ & $28(38.9 \%)$ & 0.690 \\
\hline SAH & $1(0.5 \%)$ & $1(0.8 \%)$ & $0(0 \%)$ & 0.442 \\
\hline Visual symptoms & $26(13.4 \%)$ & $10(8.2 \%)$ & $16(22.2 \%)$ & $0.006^{*}$ \\
\hline Asymptomatic & $88(45.3 \%)$ & $60(49.2 \%)$ & $28(38.9 \%)$ & 0.164 \\
\hline Type of aneurysm & & & & 0.600 \\
\hline Type A & $133(68.6 \%)$ & $82(67.2 \%)$ & $51(70.8 \%)$ & \\
\hline Type B & $61(31.4 \%)$ & $40(32.8 \%)$ & $21(29.2 \%)$ & \\
\hline Bilateral & $10(5.2 \%)$ & $3(2.5 \%)$ & $7(9.7 \%)$ & $0.027 \dagger$ \\
\hline Tandem aneurysms & $55(28.4 \%)$ & $34(27.9 \%)$ & $21(29.2 \%)$ & 0.846 \\
\hline Parent artery (SD) (mm) & $3.96 \pm 0.63$ & $3.94 \pm 0.62$ & $3.99 \pm 0.65$ & 0.639 \\
\hline \multicolumn{5}{|l|}{ Aneurysm } \\
\hline Diameter (SD) (mm) & $7.49 \pm 5.83$ & $5.90 \pm 3.81$ & $10.18 \pm 7.46$ & $0.0001 \ddagger$ \\
\hline Neck (SD) (mm) & $5.27 \pm 2.67$ & $4.58 \pm 2.11$ & $6.45 \pm 3.07$ & $0.0001 \neq$ \\
\hline \multicolumn{5}{|c|}{ PED: pipeline embolization device. } \\
\hline \multicolumn{5}{|l|}{ * Chi-square test. } \\
\hline \multicolumn{5}{|l|}{ † Mann-Whitney U test. } \\
\hline ‡ t-test. & & & & \\
\hline
\end{tabular}


$\mid$

TABLE 2. Outcome measures of 189 patients with 194 peri-ophthalmic aneurysms 


\begin{tabular}{|c|c|c|c|c|}
\hline Characteristic & Total & PED-only & PED + coils & p Value \\
\hline Size of PED (SD)(mm) & $4.18 \pm 0.46$ & $4.17 \pm 0.46$ & $4.19 \pm 0.46$ & 0.806 \\
\hline Number of PEDs & 195 & $123(63 \%)$ & $72(37 \%)$ & 0.442 \\
\hline \multicolumn{5}{|l|}{ Complications } \\
\hline Hemorrhagic & $2(1 \%)$ & $0(0.0 \%)$ & $2(2.8 \%)$ & 0.065 \\
\hline Ischemia & $12(6.2 \%)$ & $1(0.8 \%)$ & $11(15.3 \%)$ & $0.0001 \dagger$ \\
\hline Ischemia of LF & $4(2.1 \%)$ & $2(1.6 \%)$ & $2(2.8 \%)$ & 0.591 \\
\hline Visual symptoms of LF & $9(4.6 \%)$ & $5(4.1 \%)$ & $4(5.6 \%)$ & 0.729 \\
\hline IPV & $20(10.3 \%)$ & $6(3.1 \%)$ & $14(7.2 \%)$ & $0.001 \dagger$ \\
\hline New visual symptoms & $3(1.5 \%)$ & $1(0.5 \%)$ & $2(1 \%)$ & 0.287 \\
\hline Pretreatment mRS & & & & $0.036 \dagger$ \\
\hline $0-2$ & $188(99.5 \%)$ & $121(100 \%)$ & $67(98.6 \%)$ & \\
\hline $3-5$ & $1(0.5 \%)$ & $0(0 \%)$ & $1(1.4 \%)$ & \\
\hline $\mathrm{mRS}$ at LF & & & & 0.442 \\
\hline $0-2$ & $189(100 \%)$ & $121(100 \%)$ & $68(100 \%)$ & \\
\hline $3-5$ & $0(0 \%)$ & $0(0 \%)$ & $0(0 \%)$ & \\
\hline Fate of ophthalmic artery & & & & 0.498 \\
\hline No flow change & $181(93.3 \%)$ & $115(94.3 \%)$ & $66(91.7 \%)$ & \\
\hline Diminished flow & $12(6.2 \%)$ & $6(4.9 \%)$ & $6(8.3 \%)$ & \\
\hline Occlusion & $1(0.5 \%)$ & $1(0.8 \%)$ & $0(0.0 \%)$ & \\
\hline Follow-up occlusion rate & & & & $0.008^{*}$ \\
\hline Occluded (OKM-D) & $163(84 \%)$ & $96(78.7 \%)$ & $67(93.1 \%)$ & \\
\hline Incompletely occluded (OKM-A, B, C) & $31(16 \%)$ & $26(21.3 \%)$ & $5(6.9 \%)$ & \\
\hline LAF months median (range) & $6.8(5.3-20.2)$ & $6.9(5.3-20.2)$ & $6.6(5.4-16.8)$ & 0.058 \\
\hline \multicolumn{4}{|c|}{$\begin{array}{l}\text { PED: pipeline embolization device; LF: last follow up; IPV: improved postoperative vision; LAF: last } \\
\text { angiographic follow up. }\end{array}$} & : last \\
\hline
\end{tabular}


TABLE 3. Univariate and multivariate analyses of incomplete occlusion in the PED only group and the PED + coils group

\begin{tabular}{|c|c|c|c|c|c|c|}
\hline \multirow[t]{2}{*}{ Variable } & \multicolumn{3}{|c|}{ Univariate Analysis* } & \multicolumn{3}{|c|}{ Multivariate Analysis } \\
\hline & OR & $95 \% \mathrm{Cl}$ & p Value & $\mathrm{OR}$ & $95 \% \mathrm{Cl}$ & p Value \\
\hline \multicolumn{7}{|l|}{ PED-only group } \\
\hline Type B aneurysm & 4.800 & $1.922-11.987$ & 0.001 & 4.951 & $1.904-12.875$ & 0.001 \\
\hline Tandem aneurysms & 1.875 & $0.751-4.683$ & 0.178 & 1.650 & $0.608-4.478$ & 0.326 \\
\hline MDA & 1.070 & $0.969-1.181$ & 0.183 & 1.096 & $0.981-1.224$ & 0.104 \\
\hline LAF months $(<6.8) \dagger$ & 0.765 & $0.319-1.834$ & 0.548 & 1.073 & $0.408-2.823$ & 0.887 \\
\hline \multicolumn{7}{|l|}{ PED + coils group } \\
\hline Age & 0.931 & 0.849-1.020 & 0.123 & 0.952 & 0.859-1.056 & 0.352 \\
\hline Type B aneurysm & 4.083 & $0.630-26.466$ & 0.140 & 4.040 & $0.566-28.821$ & 0.164 \\
\hline Size of PED & 0.217 & $0.027-1.777$ & 0.155 & 0.290 & $0.022-3.866$ & 0.349 \\
\hline LAF months $(<6.8) \dagger$ & 0.541 & $0.085-3.448$ & 0.515 & 0.952 & $0.118-7.654$ & 0.963 \\
\hline \multicolumn{7}{|c|}{$\begin{array}{l}\text { * Also entered in the univariate analysis but not significant: sex, diabetes, hypertension, smoking, } \\
\text { presenting symptoms, maximum aneurysm diameter, aneurysm neck, number of PEDs, } \\
\text { complications, fate of ophthalmic artery. }\end{array}$} \\
\hline
\end{tabular}

TABLE 4. Univariate and multivariate analyses of visual outcomes at final follow up 


\begin{tabular}{|c|c|c|c|c|c|c|}
\hline \multirow[t]{2}{*}{ Variable } & \multicolumn{3}{|c|}{ Univariate Analysis* } & \multicolumn{3}{|c|}{ Multivariate Analysis } \\
\hline & OR & $95 \% \mathrm{Cl}$ & $\mathrm{p}$ Value & OR & $95 \% \mathrm{Cl}$ & $\mathrm{p}$ Value \\
\hline Hypertension & 3.983 & $1.024-15.496$ & 0.046 & 4.554 & $0.866-23.944$ & 0.073 \\
\hline Visual symptoms & 16.5 & $3.826-71.157$ & 0.0001 & 16.005 & $2.505-102.273$ & 0.003 \\
\hline Asymptomatic & 0.141 & $0.017-1.148$ & 0.067 & 0.491 & $0.041-5.825$ & 0.573 \\
\hline LAF months $(>6.8) \dagger$ & 3.694 & $0.748-18.257$ & 0.109 & 6.386 & $0.912-44.704$ & 0.062 \\
\hline PED + coils & 1.376 & $0.357-5.301$ & 0.642 & 1.069 & $0.214-5.343$ & 0.935 \\
\hline Type B aneurysm & 1.796 & $0.465-6.939$ & 0.395 & 1.059 & $0.203-5.512$ & 0.946 \\
\hline Occlusion of aneurysms & 0.651 & $0.129-3.290$ & 0.603 & 0.717 & $0.095-5.417$ & 0.748 \\
\hline $\begin{array}{l}\text { LAF: last angiographic fo } \\
\text { * Also entered in the univa } \\
\text { aneurysm diameter, aneut } \\
\text { † the median follow-up tir }\end{array}$ & $\begin{array}{l}\text { ow up; } P \\
\text { iate ana } \\
\text { sm necl }\end{array}$ & $\begin{array}{l}\text { D: pipeline emb } \\
\text { sis but not sigr } \\
\text { size of PED, nu } \\
\text { months. }\end{array}$ & $\begin{array}{l}\text { lization d } \\
\text { Icant } \triangle \text { ag } \\
\text { ber of } \mathrm{PE}\end{array}$ & $\begin{array}{l}\text { ice. } \\
\text { sex, smol } \\
\text { s, compli }\end{array}$ & $\begin{array}{l}\text { ng, diabetes, ma } \\
\text { tions. }\end{array}$ & num \\
\hline
\end{tabular}

TABLE 5. Comparation of aneurysm occlusion rate and visual outcomes between Type A and Type B aneurysms

\begin{tabular}{|llll|}
\hline Variable & Type A, $\mathrm{n}=133$ & Type B, $\mathrm{n}=61$ & p Value \\
\hline Total VSL & $5(3.8 \%)$ & $4(6.6 \%)$ & 0.391 \\
\hline PED-only & 82 & 40 & \\
\hline Occlusion of aneurysm & $72(87.8 \%)$ & $24(60 \%)$ & 0.0001 * \\
\hline VSL & $2(2.4 \%)$ & $3(7.5 \%)$ & 0.187 \\
\hline PED + coils & 51 & 21 & \\
\hline Occlusion of aneurysm & $49(96.1 \%)$ & $18(85.7 \%)$ & 0.118 \\
\hline VSL & $3(5.8 \%)$ & $1(4.7 \%)$ & 0.851 \\
\hline VSL: visual symptoms at final follow up; PED: pipeline embolization device. \\
* Chi-square test.
\end{tabular}

\section{Figures}



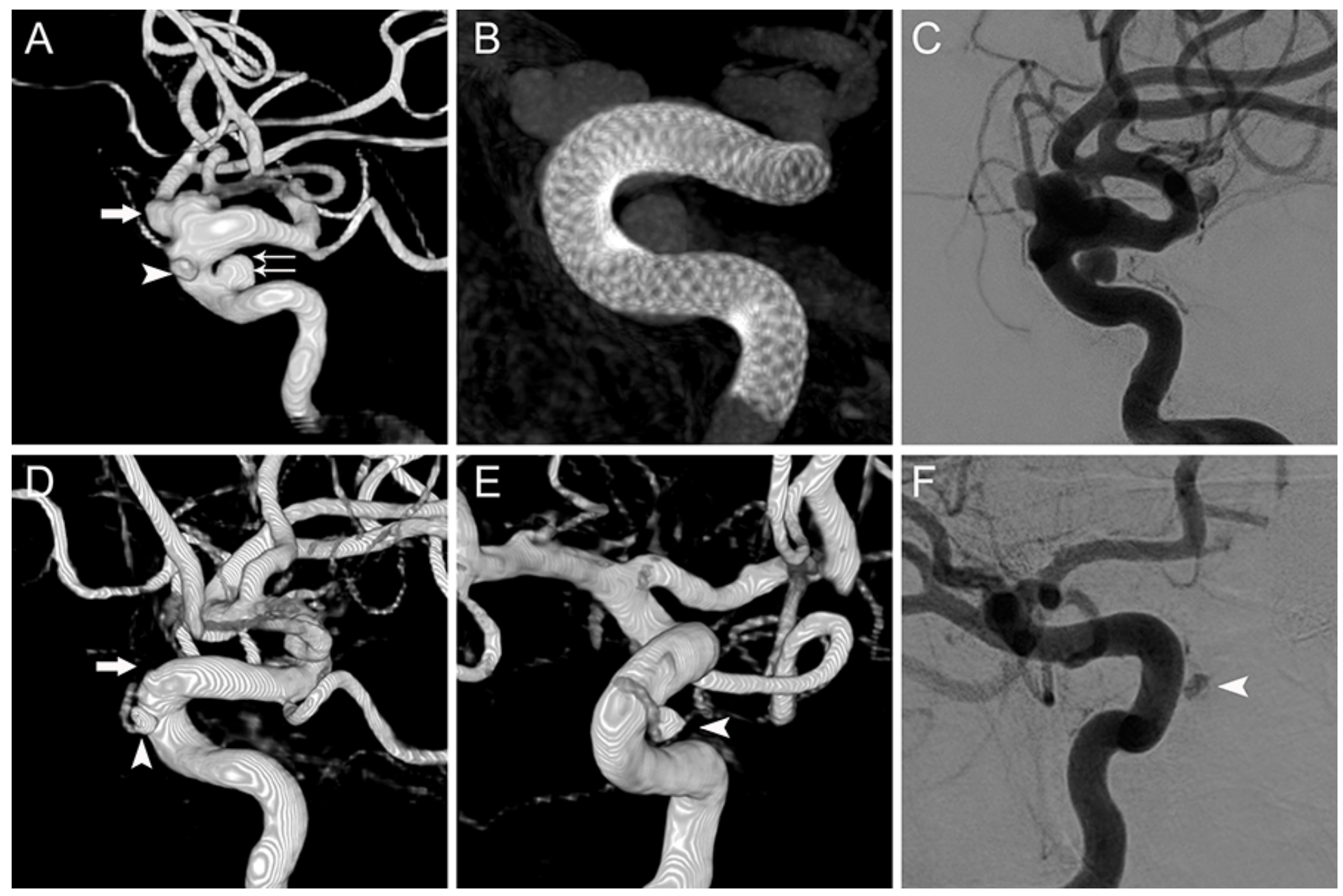

\section{Figure 1}

A 58-year-old female presented with headache for 10 years. A: Left internal carotid artery angiogram shows a Type A peri-ophthalmic aneurysm (white arrow) and multiple tandem aneurysms with a cavernous sinus segment (arrowhead and double arrows). The parent artery diameter was $3.5 \mathrm{~mm}$. B-C: The aneurysm was treated with one PED $(3.75 \times 35 \mathrm{~mm})$ only, and postoperative angiography was performed. D: On 9-month follow-up angiography (three-dimensional reconstruction), the peri-ophthalmic aneurysm was occluded, but the aneurysm located at the cavernous sinus segment was not (arrowhead), and the ophthalmic artery remained patent. E-F: Three-dimensional views and anteroposterior angiogram showing persistent filling of the aneurysm located at the cavernous sinus segment (arrowhead). 

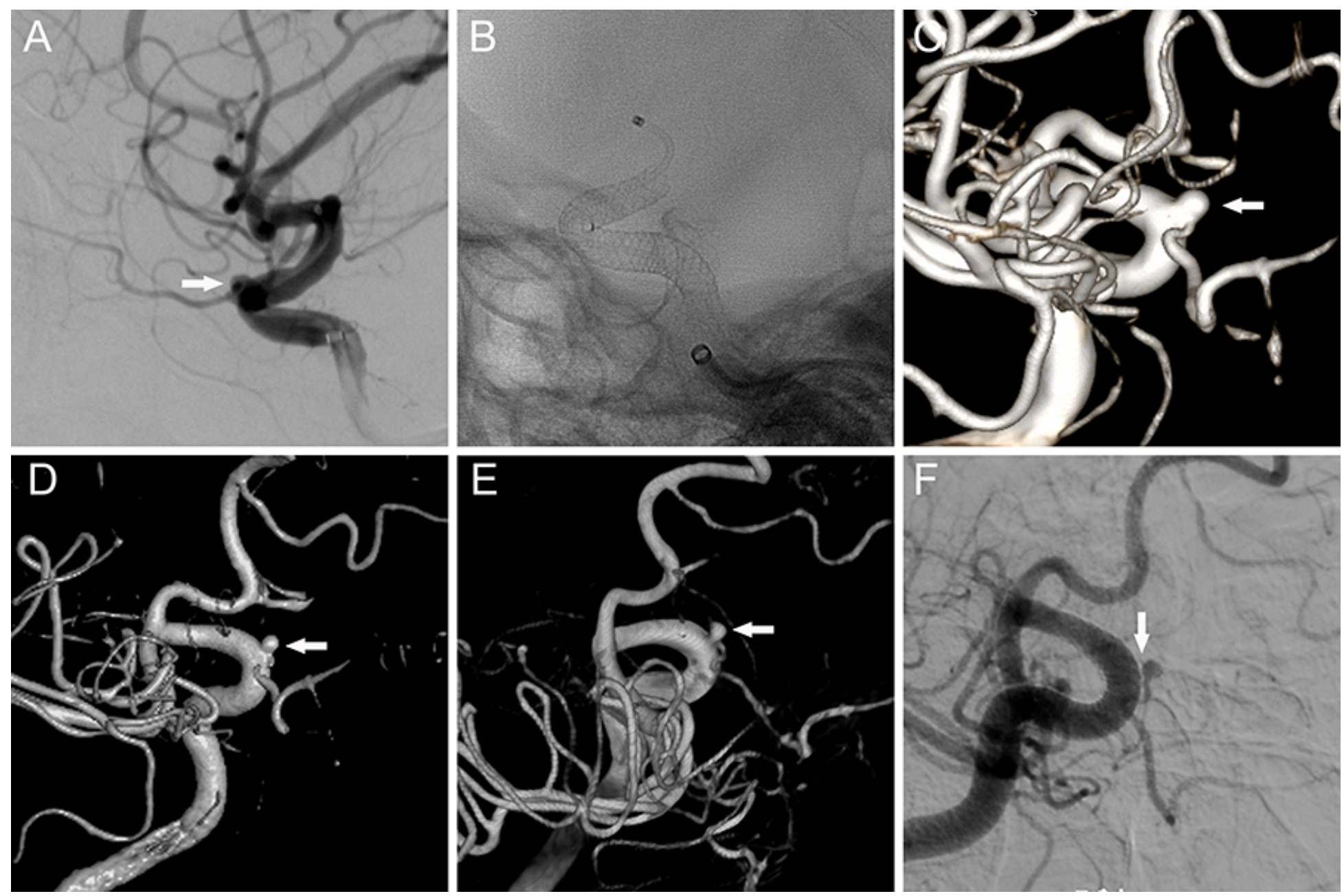

Figure 2

A 45-year-old female was admitted to hospital with an intracranial aneurysm accidentally discovered 18 days prior. A: Right internal carotid artery angiogram shows a Type B peri-ophthalmic aneurysm measuring $4.5 \times 3.1 \mathrm{~mm}$ with a 2.2-mm neck. The parent artery diameter was $4.0 \mathrm{~mm}$. B: The aneurysm was treated with one PED $(4.5 \times 25 \mathrm{~mm})$ only. C: On follow-up angiography (three-dimensional reconstruction) at 3 months, persistent filling of the aneurysm and ophthalmic artery are observed. D: On 15-month follow-up angiography (three-dimensional reconstruction), the aneurysm was not occluded (white arrow), and the ophthalmic artery remained patent. E: On 36-month follow-up angiography (threedimensional reconstruction), persistent filling of the aneurysm (white arrow) and ophthalmic artery are observed. F: Neointima formed at the neck of the un-occluded aneurysm (white arrow). This shows that continuous blood flow in the ophthalmic artery is an important factor for incomplete aneurysm occlusion. 

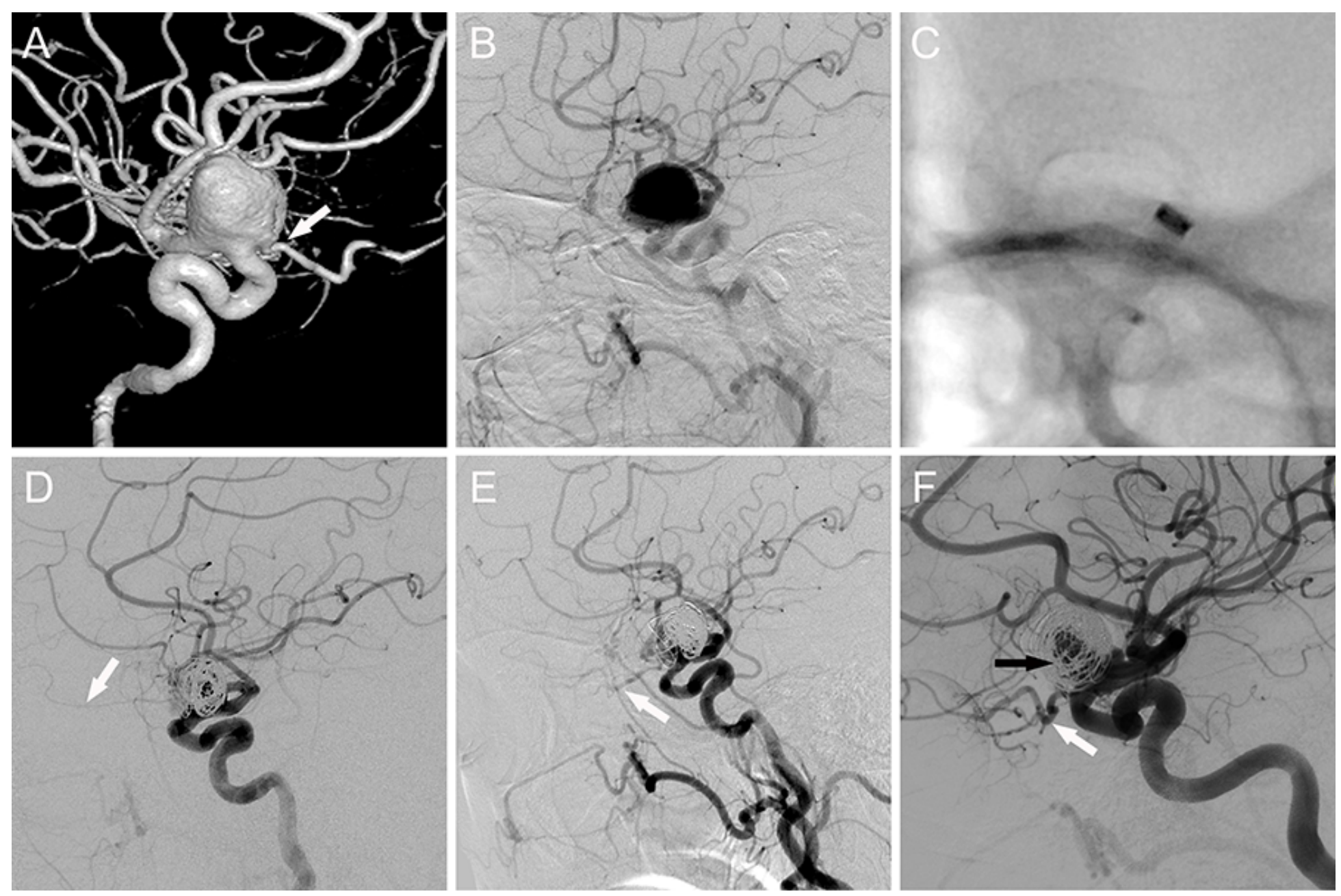

\section{Figure 3}

A 50-year-old female was admitted to hospital with an intracranial aneurysm accidentally discovered 1 week prior. A-B: Left internal carotid artery angiogram (three-dimensional reconstructed $[A]$ and lateral $[B]$ views) shows a peri-ophthalmic aneurysm. The ophthalmic artery originating from the neck of the aneurysm was defined as Type B. The aneurysm measured $18.3 \times 17.4 \mathrm{~mm}$ with a 9.68-mm neck. The diameter of the parent artery was $3.4 \mathrm{~mm}$. C: The aneurysm was treated with a PED $(4.0 \times 25 \mathrm{~mm})$. D: Postoperative angiography after packing of four coils shows that blood flow in the ophthalmic artery was significantly slowed (white arrow). E: Follow-up cerebral angiography at 5 months shows the neck of the aneurysm still filling and more obvious blood flow in the ophthalmic artery (white arrow). F: On 17-month follow-up angiography, the aneurysm was not occluded (black arrow), and blood flow in the ophthalmic artery was obvious (white arrow). 